\title{
REVIEW OF THE CURRENT INCREASE OF NOISE UNIT COST VALUES IN TRANSPORT
}

\author{
Luka Vukić1), Ivan Peronja ${ }^{1)}$, Mihaela Bukljašs', Alen Jugovićc ${ }^{3)}$ \\ ${ }^{1)}$ University of Split (Croatia) \\ ${ }^{2)}$ University of Zagreb (Croatia) \\ ${ }^{3}$ University of Rijeka (Croatia)
}

\begin{abstract}
Until recently marginalized, noise pollution has become a significant source of external transportation costs. Noise costs have currently reached a respectable share of $7 \%$, an increase of 3.5 times in the last five years. No other item of external transport costs shows even close to such growth, and the total increased by only $8 \%$ in the same period. Raising awareness of the harmfulness of this kind of contamination has contributed to better perception and detection of noise. Stricter and more thorough valorization of traffic noise has led to an increase in the share of external noise costs. Using or installing expensive noise protection equipment and new knowledge about the noise harmful effects on health contribute to the same trend. Noise pollution should be considered as an obligatory item in the assessment of sustainability in modern transport today.

Keywords: external costs; noise; traffic; unit costs; valorization
\end{abstract}

\section{Introduction}

Unlike internal transport costs related to fuel, labor, tolls, repairs, insurance, and other transportation costs paid by the carrier or the contracting authority, external costs imply negative environmental and health influence of the transport and are not compensated nor paid for by the transport user but burden the whole society. Growing science and social responsibility are putting pressure to shift the liability of damage compensation to the transport users. To determine the volume of external costs, the monetization of damage is necessary. Air pollution, climate change, traffic congestion, and accidents are the principal sources of external costs. Based on the relevant statistical data, the remaining external costs categories are responsible for only $10-15 \%$ of the total, so their significance is marginal. Road transport is the largest source of external costs in the sector (Figure 1). The total transportation external cost in EU-28 for 2016 amounted to euro (€) 987 billion, which represented 6.6\% of GDP of the Member States (Maibach et al. 2008; Van Essen et al. 2011; Korzhenevych et al. 2014; Van Essen et al. 2019). 


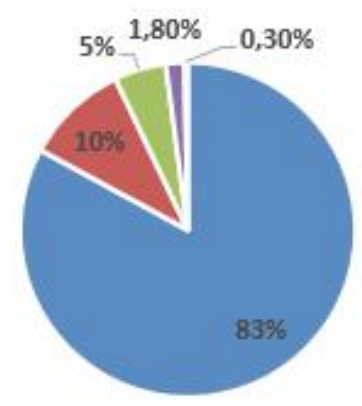

- Road " Maritime " Aviation $\|$ Rail - IWT (Inland Waterway Transport)

Figure 1. The share of different modes of transport in total external costs (EU28)

Source: Van Essen et al., 2019

In line with the European Sustainable Transport Policy ${ }^{1}$, the generated external costs should also be charged (internalized). For this purpose, there are handbooks of reputable scientific institutions used to calculate the unit prices of pollutants and updated every four to five years. By comparing the unit prices of individual pollutants in former and present publications, it is evident that they mainly increase in the periods $2008-2014$ by $35 \%$ and $2014-2019$ by $8 \%$ (Van Essen et al. 2019).

Usually, the latest unit prices are published with a delay of four years, and revaluation is necessary to obtain real values. The scale of unit pollutant price growth is influenced by economic and political factors and measures taken to reduce the negative impact of transport on the environment. In this sense, the unit prices of particular pollutants, for which successful actions have been taken to prevent and sanction pollution, will increase more gradually than those for which such measures have not been implemented or do not result in a positive outcome. The increase of only $8 \%$ in total unit prices for the last five-year period one can interpret as a consequence of successfully implemented measures for most pollutants. Reducing the sulfur content of liquid fossil fuels plays a significant role in reducing harmful emissions of sulfur oxides and particulates matter. The improvement of the combustion system in internal combustion engines reduces emissions of nitrogen oxide. The use of gas oil instead of liquid fossil fuels reduces emissions of almost all pollutants except carbon dioxide $\left(\mathrm{CO}_{2}\right)$. Switching to alternative fuels considered environmentally friendly, one can also influence the latter.

The constant technological improvements in transport vehicles and traffic superstructures followed by increasing traffic safety contribute to decreasing traffic 
accidents. Modernization of roads and railways and the utilization of intelligent transport systems reduce traffic congestion. Furthermore, awareness-raising regulations and measures to limit $\mathrm{CO}^{2}$ emissions diminish the impact of transport on climate change. Unlike the trend of gradual increase in unit pollutant prices within the principal sources of external transport costs and most of the marginal importance ones, the unit prices of external noise costs have sharply increased, which based on the currently published handbook, averaged 3 to 5 times more with a range of 0.5 to 9 . Thus, the noise has become a significant source of external costs from previous marginal significance, accounting for $7 \%$ of the total external cost of transport in the EU, including congestion costs (Figure 2).
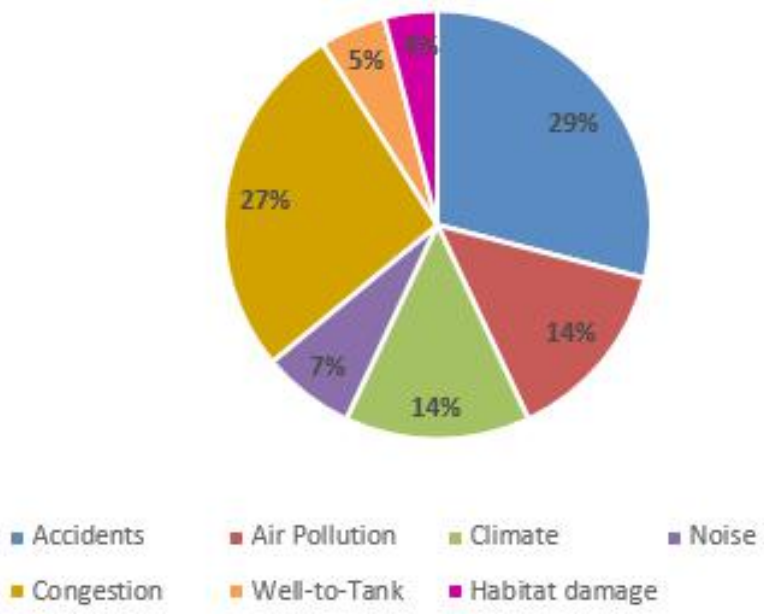

Figure 2. Share of different cost categories in total external costs of transport

Source: Van Essen et al. 2019

For this reason, the need for scientific analysis on the causes of a significant increase in unit prices of noise cost has been imposed.

\section{External costs of noise in transport}

Environmental noise is defined as noise from all sources except industrial noise in the workplace (WHO 2011) ${ }^{2}$. Transport is the largest source of noise pollution in Europe. In Switzerland, in 2014, the value of external transport costs due to noise was estimated at 1.5 billion euros, with road transport accounting for $81 \%$, rail for $15 \%$, and air for $4 \%$ (EEA 2014) $)^{3}$. According to the external transport costs handbook 2008 (Maibach et al. 2008), the share of noise in total external transport costs (EU-27) 
was also $7 \%$, but excluding congestion costs. As congestion costs, estimated at $3 \%$ of GDP (idem), amounted to $41 \%$ of total external costs (Eurostat 2008), the actual share of external noise costs was $2 \%$ of the overall transport external costs. These findings point out the conclusion that the noise share in the total transportation external costs has increased 3.5 times in the last 12 years, not recorded in any other segment of overall external costs. The predominant part of the growth refers to the latest five years. There are various theses about the causes of such indicators: the fact that little or nothing has been done to suppress traffic noise, that more and more people are exposed to it, that noise is more dangerous to health than has been previously thought. One can already conclude that all three claims are valid and emphasize that the problem is much more compound than it seems.

\section{Noise perception and detection}

Noise pollution has not been considered environmental pollution but a detrimental effect on human health that is not a completely accurate assumption, as the noise endangers the entire living world. The advantage of such a definition is that it allows valorization based on a single item basis. Thus, the total value of the external noise costs is equivalent to the valorization of health damage. There, where the noise produces a nuisance effect, which can be related to most of the environmental noise $(50-75 \mathrm{~dB})$, the people's experience differs on the individual level. The noise tolerance threshold is also a personal characteristic. Road traffic noise is tolerated easier than those from rail or air and is generally more manageable during the day than at night. Based on the data collected on the source, intensity, and direction of noise propagation, noise maps are created, which are the basis for studying and estimating the number of people exposed to noise as an element of the calculation of external costs. Newly created maps display urbanization, which implies that now more people are exposed to noise than before. It results in the correspondingly higher valorization of the damage. These maps are often inaccurate and irregularly updated so, a higher recorded estimated number of people exposed to noise is significantly lower than the realistic one (Van Essen et al. 2019).

\section{Valorization of noise pollution}

The characteristic of noise is in its variation in time and space (Vukašinović 2013), so a prediction of noise intensity and expansion is uncertain while a continuous measurement is obligatory. External costs are generally expressed as marginal, average, and total, but this has not always been the case. Marginal costs were shown from the beginning of the statistical monitoring, and therefore these items are comparable in published handbooks over different periods. The calculation of marginal values, performed by the bottom-up noise analysis (Impact Pathway Approach - IPA), applies to a single traffic vehicle (EPA 2018). However, for this very reason, the size of the marginal values is the most sensitive. Despite the higher level of the total noise at higher traffic intensity, there is a lower marginal value for an individual vehicle. Expressing external noise costs only through marginal values 
overall level are significantly lower than the real one. Complete internalization of marginal noise costs would be possible if they were calculated as $€$ per $\mathrm{dB}$ rather than $€$ per vehicle-kilometer (vkm) (EPA 2018).

Noise analysis is combined with the top-down approach through the willingness to pay (WTP) estimation, and alternatively, willingness to accept (WTA), multiplied by the number of noise-exposed persons to obtain average or total external noise costs. Regarding the demographic differences of EU citizens (from cultural to social) and the different attitudes towards this type of surveys, the results gathered are often unreliable, with citizens' responses from the unwillingness to compensate the damage to their willingness to pay only in cases where the noise level significantly decreases, e.g., 50\%. As for these weaknesses, noise monetization values are lower than the actual ones. Another method for indirect research of the economic and social impact of noise is the hedonic price method. It enables estimating of how much real estate has lost in value due to noise (Nelson 2008).

The values are processed by using the hedonic regression method and/or the noise sensitivity depreciation index (NSDI) according to the formula:

$$
N S D I=\left(\frac{\delta P}{\delta L} \frac{100}{P}\right)
$$

where $\delta \mathrm{P}$ represents the impaired value of the real estate, $\delta \mathrm{L}$ is the noise value above the permissible or tolerable limits (e.g., $50 \mathrm{~dB}$ ), and $\mathrm{P}$ is the actual value of the real estate.

Thus, the volume of a decline in real estate prices is related to the size of noise, although noise may not be the only cause of a contraction in real estate prices (for instance, a combination of congestion, air pollution, and noise is common). However, this value may not have anything to do with the impact of noise on human health and is inconsistent with the definition that noise is a threat to people, not the environment. Respondents' motivation is sometimes greater in concern for the real estate than in looking after the health condition. Furthermore, the noise is typically valorized from a single source, while in reality, there are most often multiple sources of noise. Noise unit prices expressed as $€ / \mathrm{dB} / \mathrm{t}$ in previous handbooks and studies were increased linearly with the increase of noise levels. The use of such methodology has now changed, so with the more increased noise size, the higher the weighting factor of prices is determined. The valorization of rail noise had a socalled bonus, enabling the valorization of railway noise that started at a value of 10 $\mathrm{dB}$ higher than road traffic noise. These are all methodological reasons why noise valorization was or still is on the lower levels than it should be.

Noise protection measures

Noise protection measures are distinguished between primary measures to reduce noise at a source and secondary measures such as noise propagation prevention, 
noise protection at home and workplace, economic measures, and regulations. Common to all actions is that they are compound and expensive and individually reduce the noise to a lesser extent, at most up to about $10 \mathrm{~dB}$, but usually by $2-3 \mathrm{~dB}$ (Figures 3 and 4).

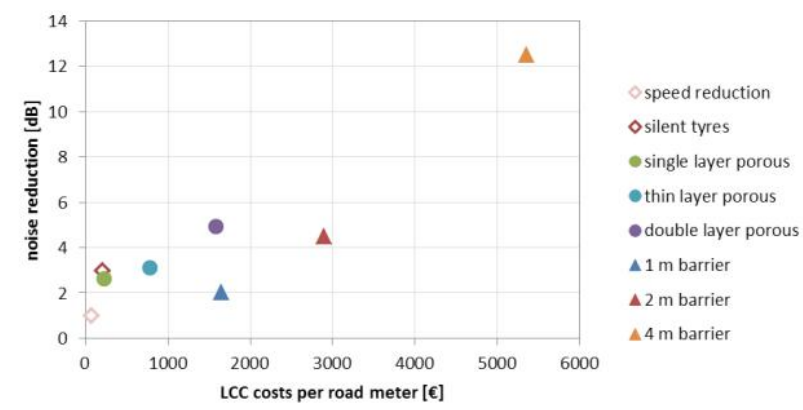

Noise reduction vs. costs per road meter for various source measures, porous road surfaces and noise barriers; noise reductions for a typical highway situation with mixed traffic (data from [15] and [41])

Figure 3. Size of noise reduction versus the cost of different techniques for highway noise reduction $(€ / \mathrm{m})$

Source: EPA, 2018

Using the $4 \mathrm{~m}$ noise barrier can result in significant noise reduction of $10 \mathrm{~dB}$ in the rail traffic and $>12 \mathrm{~dB}$ in road traffic, and it burdens the society with $2.3-5.3$ mil $€$ per $\mathrm{km}$ of life cycle costs of the product (LCC). Therefore, enormous costs limit their application.

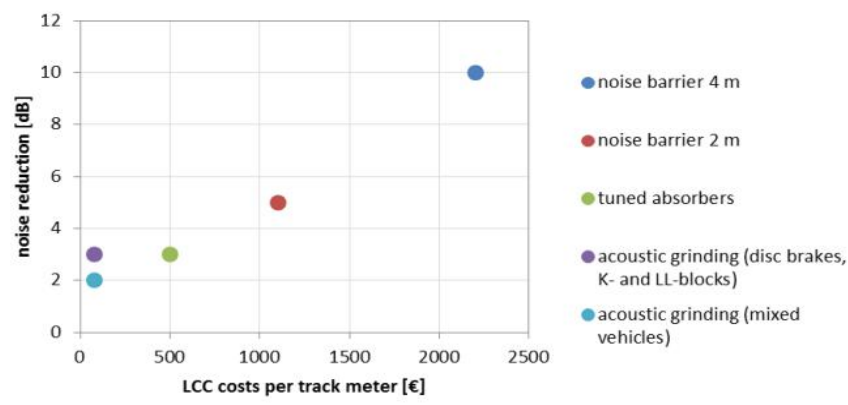

Figure 4. Size of noise reduction versus the cost of different techniques for reducing noise on the railway line $(€ / \mathrm{m})$

Source: EPA, 2018 
The subsequent installation of technical means to reduce noise levels increases the overall costs, especially if they have not been installed before as structural elements in the propulsion engine, transport infrastructure, or residential and working facilities. The transport policy of diverting freight and passenger transport from road to rail contributes to reducing overall external costs, including noise costs. There is also an exception as the new, super-fast passenger trains representing a new source of so-called aerodynamic noise. Therefore, the noise suppression measures are considered through cost-benefit analysis, and noise abatement is defined as the balance between the costs of preventing and reducing noise and the social benefits of lower environmental noise as well (EPA 2018). Thereby, maintenance costs are often neglected as well as socio-cultural and aesthetic benefits.

\section{Impact of noise on health}

Unlike some other adverse traffic effects, the causal connection of the noise impact on human health had not been clear for a long time. There are still difficulties in confirm and accept this harmful effect as a health threat, especially for noise annoyance. The most has been done in the last five years. Insisting on the World Health Organization's (WHO) definition of health, which also considers the absence of social well-being as a health disorder, noise pollution has become an indicator of the diminished quality of life on a world scale. The recent scientific findings have proven not only the well-known connection between environmental noise and hearing impairment, stress, fatigue, sleep disorders, communication difficulties, cognitive impairment in children, anxiety, and psychosomatic disorders but also the causal connection with ischemic heart disease and hypertension, including the indirect relationship with a stroke (WHO 2011). The data presented in Figure 5 indicate that around 35 million people in the European Union (EPA 2018) have suffered severe anxiety and sleep disorders due to the harmful effects of noise and have sustained a loss of about 18,000 healthy years of life.

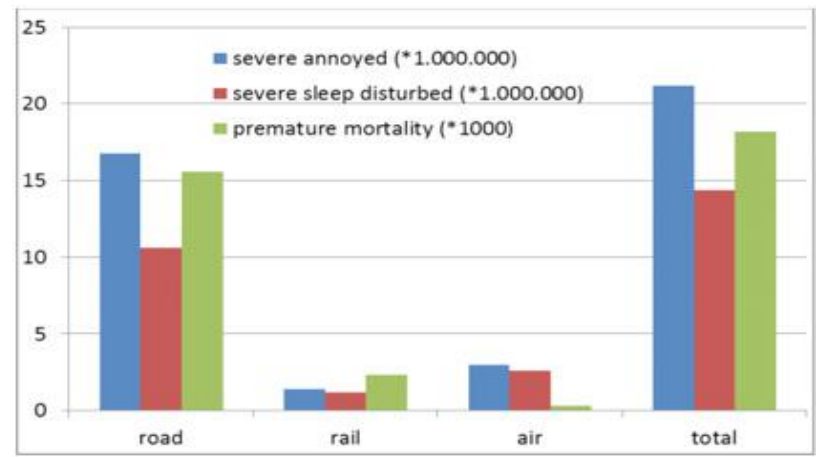

Figure 5. Impact of traffic noise on the European population (EU-27)

Source: EPA, 2018 
Considering illnesses with frequently fatal outcomes, the valorization of these diseases has led to a significant increase in the traffic noise unit cost. There are still some health disorders related to the impact of noise and not being valorized due to a lack of reliable evidence. The social cost of noise, including the costs of households and apartment insurance and eventual relocation costs, is also not considered for valorization (Van Essen et al. 2019).

\section{Discussion}

The parameter of uncertainty is a very well-known fact in the calculation of external costs. It emerges on both the pollutant source and exposure side and occurs in calculation methods each time a parameter is not measured but estimated (Jugović et al. 2018). Every scientific advance reduces uncertainty and provides evidence. Noise as an external cost is particularly uncertainty prone. The cause is partly in noise characteristics themselves, while the remaining part could be attributed to insufficient research. By updating the external cost of transport data, scientists were focused more on their principal sources, such as air pollution, traffic accidents, traffic congestion, and impacts on climate change, than with marginal ones. Today, the noise has become a significant source of external costs and an important research topic in which scientists explore how to manage noise uncertainties.

Multi-protection techniques are needed to be combined to achieve significant noise reduction, which is extremely expensive but always uncertain related to determined purpose. Determination of the lower noise tolerance limit and differences in perceptions of road, rail, and air traffic noise are also categories of uncertainty. Uneven and different policies towards some noise sources (railway bonus, linear noise monetization) and health disorders recognized as a consequence of noise exposure create additional confusion in the noise issue. The valorization of severe health consequences caused by noise exposure and an increasing number of residents results in an absolute increase in external noise costs. New findings on the nature of noise, monetization of the total social cost of noise, and the high costs of implementing noise protection measures in transport lead to a further increase and, probably, to a long period of maintaining a high share of noise costs in total external transport costs.

\section{Conclusions}

Within the overall external costs of transport, noise damage cost has been neglected so far. In the last five years, noise costs became a significant source of external transport costs. Systematic and comprehensive measurement of noise intensity in traffic, expensive equipment for noise reduction, regulations, and uncertain, subjective experience on noise as an annoyance, even when reduced, are some of the factors responsible for the current intense growth in noise unit 
costs. They indicate the need for systematic monitoring and valorization of noise pollution to determine its impact on all the segments of sustainable development of transport. It is also necessary to explore the noise occupational health impact in the sector and methods to raise social awareness.

\section{NOTES}

1. European Commission (2011), White paper, Roadmap to a Single European Transport Area - Towards a competitive and resource efficient transport system, European Commission, Brussels, Belgium.

2. World Health Organization (WHO) (2011), Burden of disease from environmental noise, WHO Regional Office for Europe, Copenhagen, Denmark.

3. European Environment Agency (2014), Noise in Europe, Report No/2014, Luxembourg: Publications Office of the European Union.

European Commission (EC) (1996) Green Paper: Future Noise Policy, European Commission, Brussels, Belgium.

\section{REFERENCES}

Maibach, M., Schreyer, C., Sutter, D., Van Essen, H.P., Boon, B.H., Smokers, R., Schroten, A., Doll, C., Pawlowska, B. \& Bak, M., 2008. Handbook on estimation of external costs in the transport sector - IMPACT D1 Version 1.1, INFRAS, Report Delft, CE Delft. The Netherlands.

Van Essen, H., Schroten, A., Otten, M., Sutter, D., Schreyer, C., Zandonella, R., Maibach, M. \& Dol, C., 2011. External Costs of Transport in Europe, Update Study for 2008, Infras, Fraunhofer ISI, CE Delft, Delft, The Netherlands.

Korzhenevych, A., Dehnen, N., Bröcker, J., Holtkamp, M., Meier, H., Gibson, G., Varma, A. \& Cox, V., 2014. Update of the Handbook on External Costs of Transport, Final report for European Commission, RICARDO-AEA, Oxfordshire, UK.

Van Essen, H., Van Wijngaarden, L., Schroten, A., De Bruyn, S., Sutter, D., Bieler, C., Maffii, S., Brambilla, M., Fiorello, D., Fermi, F., Parolin, R. \& El Beyrouty, K., 2019. Handbook on the external costs of transport, CE Delft, Delft, The Netherlands.

Jugović, A., Slišković, M. \& Vukić, L., 2018. Concept of External Costs Calculation in the Ports: Environmental Impacts. Tehnički vjesnik - Technical Gazette 25, Supplement 2, pp. 495 - 502.

Nelson, J.P., 2008. Hedonic Property Value Studies of Transportation Noise: Aircraft and Road Traffic, In: Baranzini, A. et al. (eds) (2008). Hedonic 
Methods in Housing Market Economics, Springer Sciences + Business Media, LLC. doi: 10.1007/978-0-387-76815-1_8

Vukašinović, R., 2013. Engine and motor vehicle noise problems. In: Conference Proceedings 2012/2013, Technical College of Vocational Studies. Uroševac-Leposavić Biographie.

\author{
$\triangle$ Luka Vukić \\ http://orcid.org/0000-0002-7543-7798 \\ Faculty of Maritime Studies \\ University of Split \\ Split, Croatia \\ E-mail: lvukic@pfst.hr \\ $\triangle$ Ivan Peronja \\ https://orcid.org/0000-0001-5375-6950 \\ Faculty of Maritime Studies \\ University of Split \\ Split, Croatia \\ $\triangle$ Mihaela Bukljaš \\ Faculty of Transport and Traffic Sciences \\ University of Zagreb \\ Zagreb, Croatia \\ E-mail: mihaela.bukljas@fpz.unizg.hr

$\square$ Alen Jugović
https://orcid.org/0000-0001-5031-4655
Faculty of Maritime Studies
University of Rijeka
Rijeka, Croatia
E-mail: alen.jugovic@pfri.uniri.hr

